\title{
Vaginal Hysterectomy with the Autosuture Stapler
}

\author{
XAVIER IGleSias, M.D., Ph.D., CAMIL CASTElo-BRANCO, M.D., Ph.D., and \\ CARLOS RIBAS, M.D.
}

\begin{abstract}
Our objective was to assess the applicability of hysterectomy by the vaginal route completely performed with Autosuture staples. Between January 1992 and September 1993, 5 vaginal hysterectomies using Autosuture staplers were performed by the authors. Five vaginal hysterectomies matched for age, parity, and uterine size performed by the same surgeons using reabsorbable sutures during the same period were used as case controls. No febrile morbidity, cuff infections, thrombophlebitis, bladder injury, or hemorrhage complications were observed in the 10 women who entered the study. In summary, vaginal hysterectomy can be performed with Autosutures easily, probably faster with experience, and with less oozing from the operative field, thus providing a safe procedure. (J GYNECOL SURG 10:21, 1994)
\end{abstract}

\section{INTRODUCTION}

SinCE THE FIRST REPORT BY SORANUS in the third century AD, hysterectomy has become broadly accepted as a healing and palliative procedure. This operation is the second most frequent major surgery in the United States at present. ${ }^{1}$ The majority of cases are performed in perimenopausal women, and usually hysterectomy is performed for symptomatic relief.

Dicker et al., ${ }^{2}$ comparing vaginal and abdominal approaches to hysterectomy, reported a higher complication rate for abdominal surgery. Patients who undergo vaginal hysterectomy have a shorter duration of surgery and a shorter hospital stay, lower morbidity, and faster recovery. Regardless of these incontestable benefits, more than two thirds of hysterectomies performed in the United States are done abdominally. ${ }^{3}$ The decision to perform surgery abdominally or vaginally is usually based not only on the clinical indications but also on expertise with one technique over the other. Commonly, the unequivocal advantages of the vaginal route are not considered, whereas adverse conditions (lack of mobility, poor operative exposure, previous pelvic surgery, scarring, adhesions, and uterine size) often are contemplated.

Stapling instruments have been used widely in general and gynecologic surgery, but to our knowledge, this is the first description in the medical literature of the applicability of hysterectomy by vaginal route completely performed with Autosuture stapler.

\section{SUBJECTS AND METHODS}

\section{Patients}

Between January 1992 and September 1993, we performed 10 vaginal hysterectomies, 5 using Autosuture staplers and 5 using reabsorbable sutures. Data regarding patient characteristics in the two groups are given in

Department of Obstetrics \& Gynecology, Hospital Clinic i Provincial de Barcelona, University of Barcelona Medical School, Barcelona, Spain. 
Table 1. Patient Characteristics in the Two Groups

\begin{tabular}{lcc}
\hline & Autosuture & Reabsorbable suture \\
\hline Age (years) & $49.7 \pm 3.5$ & $48.8 \pm 2.2$ \\
Para & 1 & 2 \\
$\quad 1$ & 3 & 1 \\
2 & 1 & 2 \\
$\quad 33$ & 0 & 1 \\
Previous cesarean section & 2 & 3 \\
Menopause & 3 & 2 \\
$\quad$ Yes & 2 & $70.5 \pm 6.6$ \\
$\quad$ No & 3 & 2 \\
Weight (Kg) & & 3 \\
Vaginal hysterectomy & $56.8 \pm 7.1$ & \\
Vaginal hysterectomy & $35-79$ & $58 \pm 9$ \\
$\quad$ reparative surgery & $75.5 \pm 32^{\mathrm{a}}$ & $32-76$ \\
Operating time (min) & $12.2 \pm 2$ & $12.8 \pm 1$ \\
$\quad$ Range & $10.9 \pm 2$ & $11.0 \pm 3$ \\
Specimen weight & & \\
Hemoglobin before surgery & & \\
Hemoglobin post surgery & &
\end{tabular}

${ }^{\text {a }}$ One patient had a myomatous uterus.

Table 1. Four patients had a vaginal hysterectomy only, and the other 6 had a vaginal hysterectomy with reparative surgery (anterior, posterior, or anterioposterior repairs). Table 2 lists the indications for hysterectomy in all the patients.

\section{Surgical technique}

After general or peridural anesthesia, the patient is placed in the dorsal lithotomy position with the buttocks well off the end of the table, and the vulva and vagina are fully prepared with an antiseptic solution. The bladder is catheterized, and the cervix is exposed by placing posterior and lateral vaginal retractors. Two Pozzi tenacula are used to grasp the anterior and posterior lips of the cervix. The vaginal mucosa is incised with a scalpel around the entire cervix, and while downward traction is applied on the Pozzi tenacula, a curved Mayo scissors is used to dissect the bladder off the anterior lower uterine segment and to open the peritoneal vesicouterine fold. At this point, the peritoneum of the cul-de-sac is incised with a sharp curved Mayo scissors. With the cervix on upward and lateral retraction, a Multifire EndoGIA 40-3.5 (Autosuture Company, US Surgical Corporation, Norwalk, CT) is placed in the posterior cul-de-sac, with one blade

TABLE 2. INDICATIONS FOR HYSTERECTOMY

\begin{tabular}{ll}
\hline Case & \multicolumn{1}{c}{ Indications for hysterectomy } \\
\hline & Autosuture Group \\
1 & Pelvic relaxation + stress incontinence of urine \\
2 & Uterine leiomyoma \\
3 & Pelvic relaxation \\
4 & Pelvic relaxation + stress incontinence of urine \\
5 & Adenomatous hyperplasia \\
& Reabsorbable Suture Group \\
1 & Pelvic relaxation + stress incontinence of urine \\
2 & Pelvic relaxation \\
3 & Pelvic relaxation \\
4 & Pelvic relaxation + stress incontinence of urine \\
5 & Carcinoma in situ \\
\hline
\end{tabular}




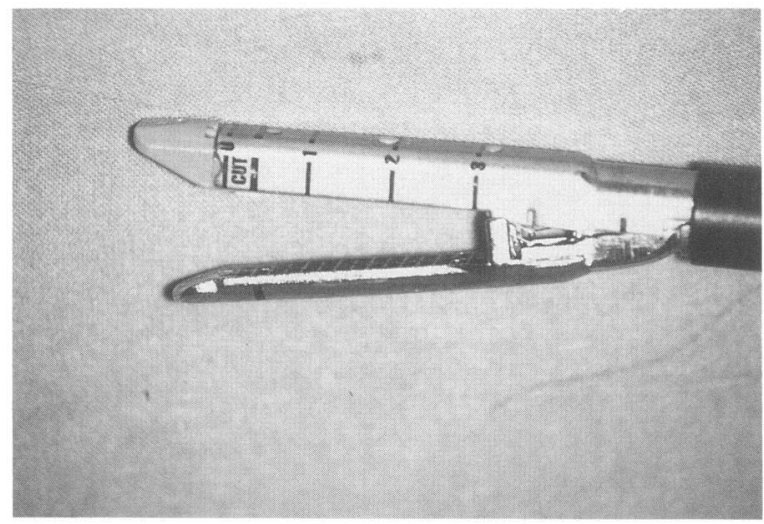

FIG. 1. The jaws of the Multifire Endo-GIA 30-3.5 (Autosuture Company, US Surgical Corporation, Norwalk, CT).

underneath the uterosacral and cardinal ligaments and the opposite blade over these ligaments immediately next to the cervix (Figs. 1, 2). In patients with large uterosacral and cardinal ligaments, we use a Multifire GIA 80-4.8 (Autosuture Company). When the cardinal and uterosacral ligaments on each side have been stapled, the uterine vessels are stapled with a Multifire EndoGIA 30-3.5 adjacent to the cervix. The cervix is retracted upward with the Pozzi tenacula, and another Pozzi is used to grasp the posterior uterine wall. The fundus is delivered posteriorly. A Multifire EndoGIA 30-3.5 is applied to the tuboovarian and round ligament close to the fundus (Fig. 3). The uterus is removed (Fig. 4), and the final steps are reperitonealization and closure of the vaginal cuff using reabsorbable sutures.

\section{RESULTS}

No febrile morbidity was observed either in the Autosuture stapler group or in the reabsorbable sutures group. Only 3 cases of urinary tract infection were recorded ( 2 for reabsorbable sutures, 1 for staplers), and no operative or postoperative bladder injury or hemorrhage complications were present. One of the patients who had a myomatous uterus required the intramyometrial coring technique for debulking. ${ }^{4}$ Time of surgery and weights of the specimens are summarized in Table 1.

\section{DISCUSSION}

Total vaginal hysterectomy is an excellent operation when removal of the uterus is indicated in cases of benign disease. The objective of this study was to assess the safety and feasibility of vaginal hysterectomy using Autosuture staplers. Stapling instruments have been used widely in general surgery, ${ }^{5-16}$ but to our

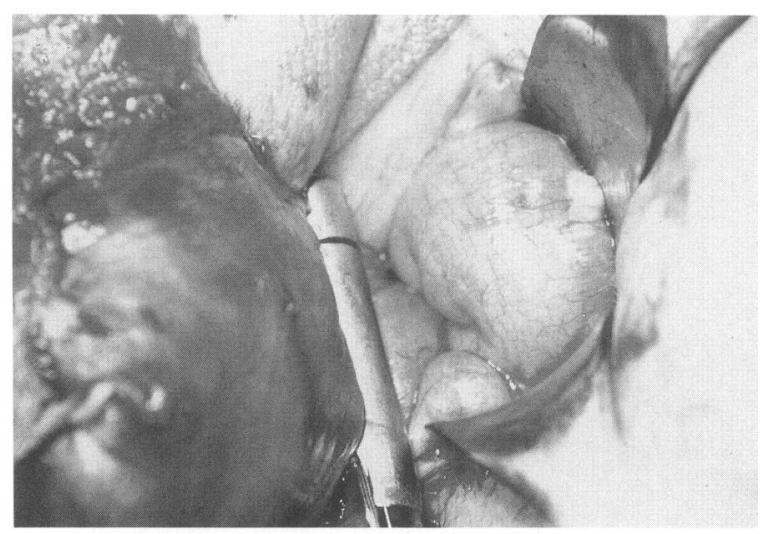

FIG. 2. The instrument embracing the uterosacral and cardinal ligaments on the left side. 


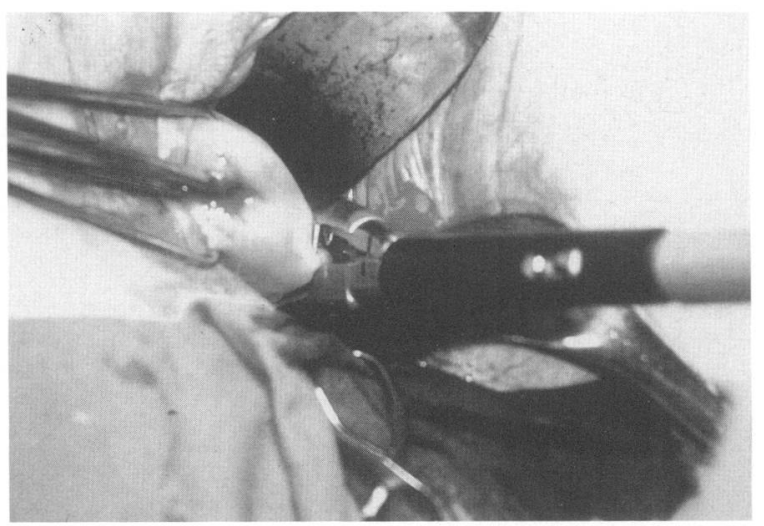

FIG. 3. The instrument is ready for cutting the right uteroovarian ligament, tube, and round ligament.

knowledge, this is the first report of a vaginal hysterectomy completely performed with Autosuture stapler. The stapler Multifire EndoGIA 50-3 has been evaluated in 5 vaginal hysterectomies. The technique described is simple and easy and can be accomplished with a minimum of operative time.

Several surgical advantages are evident when vaginal hysterectomy is performed with Autosuture stapler. First, use of the stapling device results in a minimum blood loss in the operative field, since the staples stay in the pedicles of the specimen and thus prevent oozing from the uterus. Second, the operating time should be shorter with more experience, since there are no clamps used and no stitches are placed. Third, it is easier to work inside the vagina, since no clamps, needle holders or needles are used and manipulation into the vagina is minimal, making the technique more suitable for training purposes. Theoretically, as staples are put close to the uterus without any clamps, the use of the Autosuture stapler in the vaginal hysterectomy reduces but does not eliminate ${ }^{17}$ the chance of damage to the ureter. Using clamps, however, will allow this portion of the broad ligament to be clamped in its lateral position, thus increasing the chance of ureteral damage.

Shapiro et al., in a classic study, ${ }^{18}$ suggested the risk factors for infection at the operative site after abdominal or vaginal hysterectomy. Logistic-regression analysis indicated that factors significantly associated with a higher risk of infection at the operative site were younger age, being a clinic patient, lack of antibiotic prophylaxis, increased duration of operation, and an abdominal approach. Additionally, a higher risk of infection and a decreasing effect of antibiotic prophylaxis associated with increasing duration of surgery were striking findings in their study at Boston Hospital. ${ }^{18}$ Hysterectomy performed with staples

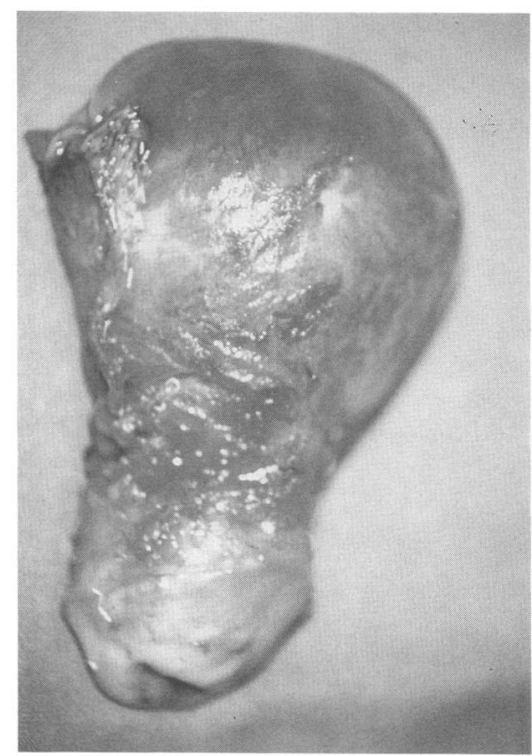

FIG. 4. The uterus with the staples placed along its right side. 
should result in a reduction in the duration of surgery compared with conventional techniques. ${ }^{19}$ Based on this finding, we might expect a decrease in the infection rate.

One drawback is the price of the staples and disposable instruments, as has been noted for laparoscopic hysterectomy. ${ }^{20}$ This should be kept in mind, and efforts should be made to lower the expense. However, with minimal experience, the surgeon can perform a vaginal hysterectomy with the Autosuture stapler in a very short time, faster than with traditional sutures. This will result in decreased operating room costs, which may compensate for the expense of the stapling equipment.

In summary, vaginal hysterectomy can be performed with Autosutures easily, probably faster with experience, and with less oozing from the operative field, thus enabling a safe procedure.

\section{REFERENCES}

1. Benrubi GA. History of hysterectomy. J Fl Med Assoc 1988;75:533.

2. Dicker RC, Greenspan JR, Strauss LT, et al. Complications of abdominal and vaginal hysterectomy among women of reproductive age in the United States. Am J Obstet Gynecol 1982;144:841.

3. Lazarus ML, Levanthal ML. Total abdominal and vaginal hysterectomy: A comparison. Am J Obstet Gynecol 1985;61:2.

4. Kovac SR. Intramyometrial coring as an adjunct to vaginal hysterectomy. Obstet Gynecol 1986;67:131.

5. Ravo B, Rosales C, Serino F, Castagneto M. The use of absorbable staples for construction of a bladder tube. Surg Gynecol Obstet 1991;173:29.

6. Graeber GM, Collins JJ Jr, DeShong JL, Murray GF. Are sutures better than staples for closing bronchi and pulmonary vessels? Ann Thorac Surg 1991;51:901.

7. Hoskins IA, Ordorica SA, Frieden FJ, Young BK. Performance of cesarean section using absorbable staples. Surg Gynecol Obstet 1991;172:108.

8. Fok M, Ah-Chong AK, Cheng SW, Wong J. Comparison of a single layer continuous hand-sewn method and circular stapling in 580 oesophageal anastomoses. Br J Surg 1991;78:342.

9. Jansson OK, Zilling TL, Walther BS. Healing of colonic anastomoses: Comparative experimental study of glued, manually sutured, and stapled anastomoses. Dis Colon Rectum 1991;34:557.

10. Dziki AJ, Duncan MD, Harmon JW, et al. Advantages of handsewn over stapled bowel anastomosis. Dis Colon Rectum 1991;34:442.

11. Clayer M, Southwood RT. Comparative study of skin closure in hip surgery. Aust NZ J Surg 1991;61:363.

12. Wolfensberger M, Simmen D. Staple closure of the hypopharynx after diverticulectomy and total laryngectomy. Dysphagia 1991;6:26.

13. Marrero MA, Corfman RS. Laparoscopic use of sutures. Clin Obstet Gynecol 1991;34:387.

14. Almekinders LC. Tips of the trade 32. Gradual closure of fasciotomy wounds. Orthop Rev 1991;20:82.

15. Buka NJ. Absorbable staples in abdominal hysterectomy. Surg Gynecol Obstet 1988;166:174.

16. Cruikshank SH, Pixley RL. Methods of vaginal cuff closure and preservation of vaginal depth during transvaginal hysterectomy. Obstet Gynecol 1987;70:61.

17. Woodland MB. Ureter injury during laparoscopy-assisted vaginal hysterectomy with the endoscopic linear stapler. Am J Obstet Gynecol 1992;167:756.

18. Shapiro M, Muñoz A, Tager IB, Schoenbaum SC, Polk F. Risk factors for infection at the operative site after abdominal or vaginal hysterectomy. N Engl J Med 1982;307:1661.

19. Stovall TG, Summitt RL Jr, Lipscomb GH, Ling FW. Vaginal cuff closure at abdominal hysterectomy: Comparing sutures with absorbable staples. Obstet Gynecol 1991;78:415.

20. Baggish MS. The most expensive hysterectomy. J Gynecol Surg 1992;8:57.

Address reprint requests to: Camil Castelo-Branco, M.D., Ph.D. Department of Obstetrics \& Gynecology Hospital Clinic i Provincial de Barcelona 